\title{
ENRAIZAMENTO DE MINIESTACAS DE AMEIXEIRA
}

\author{
ADILSON TONIETTO², GERSON RENAN DE LUCES FORTES ${ }^{3}$, JOÃO BAPTISTA DA SILVA ${ }^{4}$
}

RESUMO - Com este trabalho, objetivou-se maximizar o rendimento do número de estacas enraizadas por ramo. Foram utilizados ramos do ano de duas cultivares de ameixeira (Reubennel e Pluma 7) eliminando-se a porção apical de cada ramo, com diâmetro inferior a $2 \mathrm{~mm}$. As miniestacas foram obtidas fazendo-se um corte em bisel distante no mínimo $0,5 \mathrm{~cm}$ acima da gema e outro junto à gema subseqüente. Em seguida, foram mergulhadas em uma solução de ácido indolbutírico (AIB) $2000 \mathrm{mg}$. $\mathrm{L}^{1}$, por cinco segundos, e utilizou-se, como testemunha, uma solução composta de água destilada misturada ao mesmo volume de álcool utilizado para diluir o AIB. As miniestacas foram colocadas para enraizar em bandejas de isopor contendo, como substrato, uma mistura de cinza de casca de arroz e vermiculita $(2: 1 \mathrm{v} / \mathrm{v})$, obedecendo-se à seqüência em que foram retiradas dos ramos. Parte das estacas permaneceram em substrato coberto com plástico transparente com espessura de 20 micras e parte em substrato descoberto. O delineamento experimental foi completamente casualizado, em esquema fatorial 2×2×2 (cultivares, soluções, plástico), com quatro repetições, utilizando-se de 15 miniestacas por parcela. Após 39 dias, foram avaliados o enraizamento (\%), o comprimento e o número de raízes. A cultivar Pluma 7 apresenta maior potencial de enraizamento e maior sensibilidade ao AIB. Estacas de gema única possuem capacidade de formar raízes. Toda a extensão do ramo, de cultivares de ameixeiras que respondam ao ácido indolbutírico, pode ser utilizada como estaca na formação de mudas. $\mathrm{O}$ plástico reduz o enraizamento de estacas. O AIB aumenta o enraizamento, o número e o comprimento de raízes dos cultivares estudadas.

Termos de indexação: ácido indolbutírico, temperatura, propagação, Prunus salicina

\section{ROOTING OF MINI-CUTTINGS PLUM}

\begin{abstract}
The trial aimed to maxim yield of the number of plum cuttings per branch. Growing shoots of two plum cultivars (Reubennel and Pluma 7) were used. The apical portion with diameter shorter than $2 \mathrm{~mm}$ was eliminated. The mini-cuttings were obtained by making a $0.5 \mathrm{~cm}$ cut above the bud and another one next to the subsequent bud. The mini-cuttings were immersed in a solution of IBA $2000 \mathrm{mg} . \mathrm{L}^{-1}$ for five seconds. As control, a solution composed of distilled water mixed with the same volume of methyl alcohol was used to dissolve the IBA solution. The mini-cuttings were placed to root in an expanded polyesterene tray containing a mixture of rice husk ash and vermiculite $(2: 1 \mathrm{v} / \mathrm{v})$ as substrate. Half of this material was covered with $(20$ micra) thick transparent plastic and the other part without it. The experiment was carried out in a complete randomized block by using a factorial $2 \times 2 \times 2$ (cultivar, IBA and plastic film) with four replications and fifteen mini-cuttings per plot. After 39 days the percentage of rooting, root number and length were evaluated. Pluma 7 cultivar showed the highest rooting ptential and the highest sensibility to IBA. One - bud cuttings are able to form root. It is possible to obtain rooted cuttings with the whole shoot when they are treated with IBA. It was observed that plastic film reduced the root cutting. IBA increases the rooting, the number and root length of the studied cultivars.
\end{abstract}

Index terms: indolbutiric acid, temperature, propagation, Prunus salicina

\section{INTRODUÇÃO}

A técnica de multiplicação vegetativa mais comumente utilizada na clonagem de plantas lenhosas, em larga escala, tem sido a estaquia que, embora seja utilizada com sucesso para algumas espécies, ou mesmo para alguns cultivares dentro de uma mesma espécie, não tem obtido sucesso para outras (Assis e Teixeira, 1999). Estes autores citaram que a cultura de tecidos tem se apresentado como uma alternativa viável de clonagem de espécies lenhosas para a produção comercial de mudas e formação de pomares. Denardi e Leite (1996) citaram ainda que, com a cultura de meristemas, existe a possibilidade de multiplicar, em escala geométrica e em ciclos relativamente curtos, grande número de espécies vegetais a partir de um único meristema. Porém, isto requer alguns quesitos que podem não estar ao alcance do produtor.

A estaquia é uma técnica que possibilita a obtenção de mudas de ameixeira, em um ciclo vegetativo, sem a necessidade de enxertia e, portanto, com menor custo comparado à muda tradicional enxertada. Aliados a isto, Finardi e Camelatto (1995) atribuíram, às mudas com sistema radicular de ameixeira, tolerância às condições de asfixia por encharcamento do solo, enquanto mudas de ameixeiras enxertadas sobre pessegueiro não sobrevivem em tais condições.

A propagação por estacas baseia-se na faculdade de regeneração dos tecidos e emissão de raízes, devendo a estaca, ou fragmento dela, conter no mínimo uma gema (Simão, 1998). Com relação ao tamanho das estacas, Fachinello et al. (1994) relataram que o comprimento e o diâmetro variam conforme a espécie e o tipo de estaca. Estacas lenhosas podem ter

1 (Trabalho 181/2000). Recebido: 17/08/2000. Aceito para publicação: 22/07/2001.

2 Bolsista do CNPq, Doutorando em Fruticultura de Clima Temperado, FAEM/UFPEL, Cx. P. 354, CEP;96010-900, Capão do Leão/RS. tonietto@ufpel.tche.br

3 Dr. Pesquisador Embrapa Clima Temperado

4 Engenheiro Agrônomo, Livre Docente, Dr. Professor Titular (aposentado) do IFMC/UFPEL, Bolsista do CNPq. 
comprimento variável de 20 a $30 \mathrm{~cm}$ e diâmetro entre 0,6 e 2,5 cm. Estacas semilenhosas apresentam um comprimento, em geral, de 7,5 a $15 \mathrm{~cm}$, e estacas herbáceas podem ser ainda menores. Vários autores (Kersten et al., 1994; Tonietto et al., 1997; Dutra et al., 1998), metodologicamente, limitaram o tamanho das estacas de ameixeira sem uma base lógica para tal limite.

Assis e Teixeira (1999) afirmaram que o controle do desenvolvimento de raízes adventícias é influenciado por substâncias reguladoras de crescimento, apresentando uma concentração ótima que pode variar entre espécies, populações ou clones, algumas promovendo e outras inibindo. Bose e Mandal (1972) citaram que o ácido indolbutírico (AIB) é um dos reguladores de crescimento mais aplicados, sendo efetivo para um grande número de espécies.

A diferença de enraizamento entre cultivares de ameixeira tem sido relatada em vários trabalhos, sendo que Dutra et al. (1998) verificaram que as cultivares Frontier e Ace apresentaram maior facilidade de emitir raízes do que as cultivares Roxa de Itaquera, Sungold, Beauty e Reubennel. Observaram também que a utilização de AIB na concentração de $3000 \mathrm{mg} . \mathrm{L}^{-1}$ resultou em enraizamento igual ou superior ao controle, para todas as cultivares. Rathore (1983) conseguiu $100 \%$ de enraizamento em estacas semilenhosas de ameixeira Santa Rosa ao mergulhar a base destas em solução de AIB $6000 \mathrm{mg} . \mathrm{L}^{-1}$ por cerca de um minuto. Finardi e Camelatto (1995) recomendaram a utilização de solução de AIB na concentração de $2000 \mathrm{mg} . \mathrm{L}^{-1}$ para o enraizamento de estacas lenhosas de ameixeira.

$\mathrm{O}$ aquecimento do substrato de enraizamento também é citado como um tratamento que favorece o enraizamento. Fiorino e Loreti (1963) citaram que a temperatura possui eficiência diferente conforme o substrato, cultivar ou porta-enxerto, considerando boas as temperaturas entre $10^{\circ} \mathrm{Ce} 20^{\circ} \mathrm{C}$. Erez (1984) obteve enraizamento maior em estacas colocadas em substrato coberto com filmes de polietileno $(0,05 \mathrm{~mm})$ do que em substrato descoberto.

Este trabalho objetivou estudar a obtenção de mudas de ameixeira através de estacas contendo uma gema, de forma a otimizar o número de estacas obtidas por ramo.

\section{MATERIAL E MÉTODOS}

O experimento foi conduzido em casa de vegetação equipada com sistema de nebulização, localizado nas dependências do Departamento de Fitotecnia da Faculdade de Agronomia Eliseu Maciel/UFPel, Câmpus Universitário, PelotasRS.

Foram coletados, em 9-11-1999, ramos do ano de plantas de ameixeira (Prunus salicina Lindl) cultivares Reubennel e Pluma 7 , pertencente a um pomar com quatro anos de idade, localizada no município de Capão do Leão. A porção apical de cada ramo, quando inferior a $2 \mathrm{~mm}$ foi eliminada. De cada ramo, foram retiradas quinze estacas, fazendo-se um corte em bisel no mínimo $0,5 \mathrm{~cm}$ acima da gema e outro junto à gema subseqüente, ficando a estaca constituída de uma gema e sendo denominada de miniestaca. As miniestacas foram mergulhadas em uma solução de AIB $2000 \mathrm{mg} . \mathrm{L}^{-1}$, dissolvido em álcool etílico, por cinco segundos. Utilizou-se, como testemunha, uma solução composta de água destilada misturada a idêntico volume de álcool utilizado para dissolver o AIB. Em seguida, as mini-estacas foram colocadas para enraizar em bandejas de isopor contendo como substrato uma mistura de cinza de casca de arroz e vermiculita $(2: 1 \mathrm{v} / \mathrm{v})$. A seqüência de colocação das miniestacas nas células das bandejas obedeceu àquela em que foram retiradas dos ramos. Parte das miniestacas permaneceram em substrato coberto com plástico transparente de 20 micras de espessura e parte em substrato descoberto.

Para a leitura das temperaturas dos substratos, foram instalados dois geotermômetros na profundidade de $2 \mathrm{~cm}$, um no substrato coberto e outro no substrato descoberto, sendo sua posição sorteada. Foram escolhidos, ao acaso, quatro dias nas duas primeiras semanas em que o experimento foi instalado. Nestes dias, foram feitas leituras das 8 às 16 horas, em intervalos de duas horas, e uma leitura às 17 horas. Também foi instalado um termoigrógrafo de onde foram obtidas as temperaturas do ambiente.

O delineamento experimental foi completamente casualizado, em esquema fatorial $2 \times 2 \times 2$ (cultivares, soluções e plástico), e quatro repetições com 15 estacas por parcela. O material permaneceu nesta condição onde, após 39 dias, foram avaliados a percentagem de estacas enraizadas, número e comprimento de raízes.

\section{RESULTADOS E DISCUSSÃO}

As miniestacas foram eficientes na formação de raízes (Figura 1) apresentando cerca de $99 \%$ de enraizamento na cultivar Pluma 7, demonstrando também que todas as porções do ramo desta cultivar apresentaram potencial para a formação de mudas. No entanto, a eficiência foi dependente da cultivar e da utilização do ácido indolbutírico (AIB), como se pode observar na Figura 2 .

A diferença de enraizamento entre cultivares é uma característica já conhecida. Dutra et al. (1998), estudando seis cultivares de ameixeira, observaram que a cultivar Reubennel apresentou os menores resultados, 4,54\% de enraizamento, mesmo com a utilização de ácido indolbutírico a $3000 \mathrm{mg} . \mathrm{L}^{-1}$. Os autores utilizaram estacas medianas com $15 \mathrm{~cm}$ de comprimento, e o maior percentual de enraizamento foi obtido com a cultivar Frontier (50,21\%). Comparando apenas a cultivar Reubennel, nota-se que a utilização de miniestacas apresentou resultado maior que os obtidos pelos autores acima. No entanto, não se pode atribuir o maior resultado ao tamanho da estaca, pois houve diferença, entre os experimentos, na época de coleta e na concentração do ácido indolbutírico.

Observa-se, na Figura 3, que a cobertura plástica manteve a temperatura do substrato acima do substrato não coberto, nos períodos em que foram feitas as leituras.

Em alguns períodos, o substrato coberto alcançou temperaturas médias de até $2^{\circ} \mathrm{C}$ acima do substrato sem cobertura plástica. Mas este efeito foi significativamente negativo para o enraizamento, obtendo-se, em média, $27,25 \%$ e $34,47 \%$ para o material com e sem plástico, respectivamente. Geralmente, o aquecimento de substrato é utilizado no enraizamento de estacas lenhosas. Alguns trabalhos citam a utilização de temperaturas entre $15^{\circ} \mathrm{C} \mathrm{e} 25^{\circ} \mathrm{C}$ e até $30^{\circ} \mathrm{C}$ (Loach, 1988). Nota-se, na Figura 3 , que o substrato descoberto apresentou temperatura superior a 


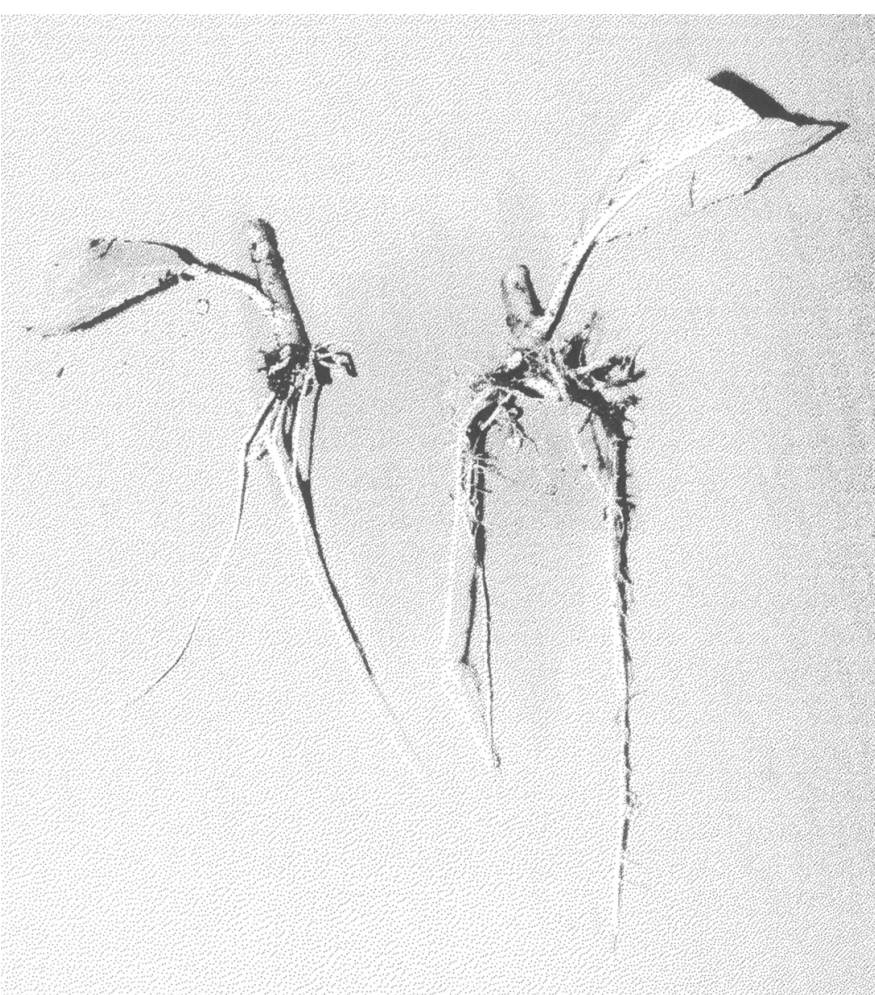

FIGURA 1 - Miniestacas de ameixeira enraizadas. Pelotas, 1999.

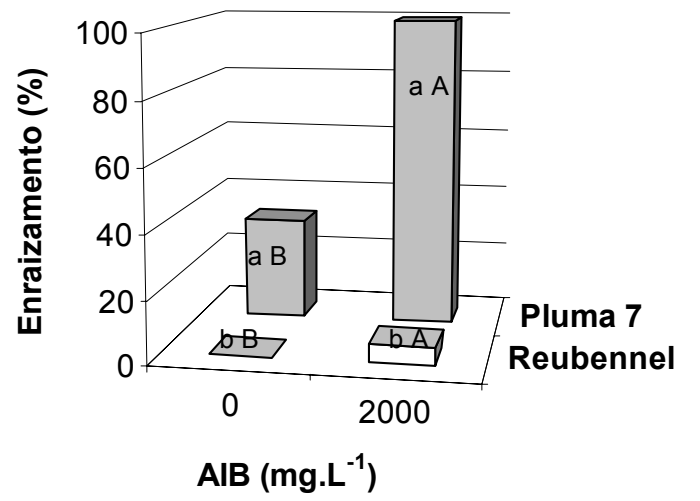

FIGURA 2 - Enraizamento de miniestacas de ameixeira, tratadas com ácido indolbutírico. Pelotas, 1999. (Médias seguidas por letras distintas, minúsculas entre cultivares e maiúsculas entre soluções, diferem estatisticamente pelo teste de Duncan, ao nível de $5 \%$ de probabilidade).

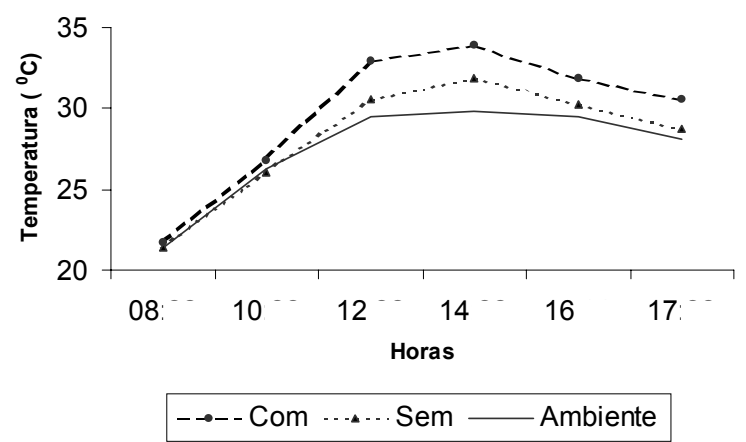

FIGURA 3 - Evolução da temperatura do substrato, a $2 \mathrm{~cm}$ de profundidade, com e sem cobertura plástica. Pelotas, 1999. (Médias de leituras feitas em 4 dias).

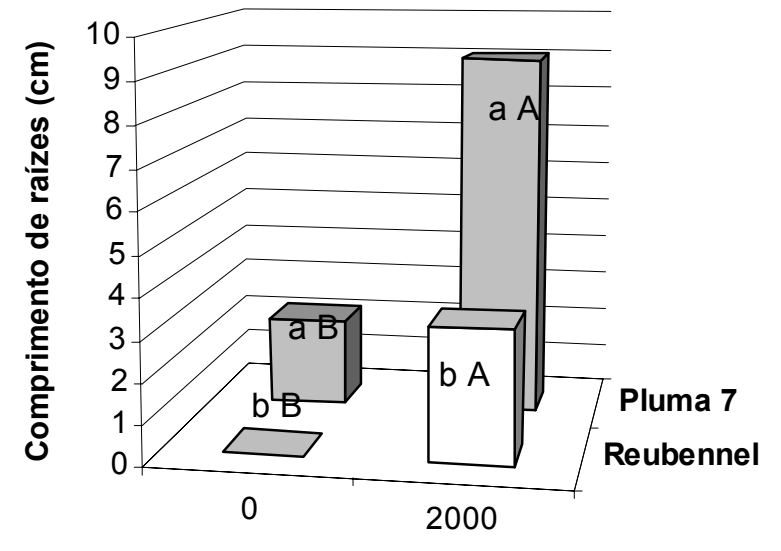

AlB (mg. $\left.{ }^{-1}\right)$

FIGURA 4 - Comprimento de raiz de miniestacas de ameixeira, cultivares Reubennel e Pluma 7, tratadas com AIB. Pelotas, 1999. (Médias seguidas por letras distintas, minúsculas entre cultivares e maiúsculas entre soluções, diferem estatisticamente pelo teste $\mathrm{F}$, ao nível de $5 \%$ de probabilidade).

$30^{\circ} \mathrm{C}$ e o coberto, temperaturas ainda mais elevadas, o que pode ter prejudicado a indução de raízes.

A impossibilidade de acompanhamento das temperaturas noturnas não permite fazer qualquer inferência com relação às mesmas.

A utilização do AIB aumentou significativamente o número de raízes por estaca, passando de 1,6 (testemunha) para 4,2 (2000 mg. $\left.\mathrm{L}^{-1}\right)$. Também houve diferença significativa no número de raízes entre cultivares, obtendo-se 0,63 para Reubennel e 5,22 para Pluma 7. O AIB é um dos biorreguladores mais utilizados para a indução de raízes e, segundo Assis e Teixeira (1999), o genótipo é um dos fatores que influenciam o enraizamento, existindo uma grande variação entre espécies, cultivares e clones em relação à maior ou menor habilidade natural em formar raízes. Portanto, pode-se atribuir ao biorregulador e à maior sensibilidade da cultivar Pluma 7 a este, os melhores resultados obtidos pela cultivar, em percentagem de enraizamento e número de raízes.

O AIB e a cultivar interagiram na variável comprimento de raiz, obtendo-se o maior comprimento com a cultivar Pluma 7 tratada com AIB a 2000 mg.L - $^{-1}$ (Figura 4).

Possivelmente, com a indução e provável antecipação da formação de raízes com a utilização do AIB, houve um período maior para o crescimento das raízes dentro do substrato, tendo assim o AIB um efeito indireto sobre o comprimento de raiz.

A cobertura plástica não influenciou o número nem o comprimento de raízes.

\section{CONCLUSÕES}

- A cultivar Pluma 7 apresenta maior potencial de enraizamento e maior sensibilidade ao AIB do que a cultivar Reubennel.

- Miniestacas possuem capacidade de formar raízes.

- Toda extensão do ramo, de cultivares de ameixeiras que respondam ao ácido indolbutírico, pode ser utilizada como estaca 
na formação de mudas.

- O plástico reduz o enraizamento, não afetando o número e o comprimento de raízes por estaca.

- O AIB aumenta o enraizamento, o número e comprimento de raízes das duas cultivares.

\section{REFERÊNCIAS BIBLIOGRÁFICAS}

ASSIS, T. F. de; TEIXEIRA, S. L. Enraizamento de plantas lenhosas. In: TORRES, A. C.; CALDAS, L. S.; BUSO, J. A. (Ed.) Cultura de tecidos e transformação genética de plantas. Brasília: Embrapa-SPI/ Embrapa-CNPH, 1999. v.1, p.261-296.

BOSE , T. K.; MANDAL, D. P. Mist propagation of tropical plants. Indian Horticulture, New Delhi, v.17, n.1, p.25-26, 1972.

DENARDI, F.; LEITE, G. Enxertia de mergulhia contínua: nova técnica de multiplicação rápida de porta-enxertos de macieira. Agropecuária Catarinense, Florianópolis, v.9, n.4, p.16-18, 1996.

DUTRA, L. F.; TONIETTO, A.; KERSTEN, E. Efeito da aplicação prévia de ethephon em ameixeira (Prunus salicina Lindl) e do IBA no enraizamento de suas estacas. Scientia Agrícola, Piracicaba, v.55, n.2, p.296-304, 1998.

EREZ, A. Improving the rooting of peach hardwood cuttings under field conditions. HortScience, Alexandria, v.119, n.2, p. 245 $247,1984$.

FACHINELLO, J. C.; HOFMANN, A.; NACHTIGAL, J. C.;
KERSTEN, E.; FORTES, G. R. de L. Propagação de plantas frutíferas de clima temperado. Pelotas: Editora e Gráfica UFPEL, 1994. 179p.

FINARDI, N. L.; CAMELATTO, D. Obtenção de mudas de ameixeira cv. Santa Rosa a partir de estacas lenhosas. Pelotas: EMBRAPA/CPACT, 1995. 4p. (Comunicado Técnico, 1).

FIORINO, P.; LORETI, F. La propagazione del pesco per talea legnosa con la tecnica del riscaldamento basale. In: ATTI DEL CONGRESSO DEL PESCO, 1963, Verona.p.483-495. 1963.

KERSTEN, E.; TAVARES, S. W.; NACHTIGAL, J. C. Influência do ácido indolbutírico no enraizamento de estacas de ameixeira (Prunus salicina Lindl.). Revista Brasileira de Fruticultura, Cruz das Almas, v.16, n.1, p.215-222, 1994.

LOACH, K. Controlling environmental conditions to improve adventitious rooting. In: Adventitious root formation in cuttings, Portland: Discorides Press, 1988. p.249-273.

RATHORE, D. S. Note on the effect of indolebutyric acid on rooting of plum cuttings under mist. Indian Journal of Horticulture, Bangalore, v.40, n.3-4, p.205-206, 1983.

SIMÃO, S. Tratado de fruticultura, Piracicaba:FEALQ, 1998. $760 \mathrm{p}$.

TONIETTO, A; DUTRA, L. F.; KERSTEN, E. Influência do ácido indolbutírico e ethefon no enraizamento de estacas de pessegueiro (Prunus persica (L.) Batsch). Ciência Rural, Santa Maria, v.27, n.4, p.567-569, 1997. 